\title{
Parkinson's disease effect on autonomic modulation: an analysis using geometric indices
}

\author{
Efeito da doença de Parkinson na modulação autonômica: análise por meio de \\ índices geométricos
}

\author{
Mileide Cristina STOCO-OLIVEIRA', Ana Laura RICCI-VITOR', Laís Manata VANZELLA', \\ Heloisa Balotari VALENTE1. Vitor Eduardo dos Santos SILVA', Larissa Borba ANDRE'1, \\ Augusto Cesinando de CARVALHO' ${ }^{1}$, David Matthew GARNER², Luiz Carlos Marques VANDERLEI
}

\begin{abstract}
Background: Parkinson's disease (PD) produces autonomic changes, indicating lower parasympathetic modulation and global variability, but these changes need further studying regarding geometric methods. Objective: To investigate the autonomic modulation in individuals with PD using heart rate variability (HRV) indices obtained through geometric methods. Methods: This is a cross-sectional study that assessed 50 individuals, split into two groups: PD group (PDG; $n=26 ; 75.36 \pm 5.21$ years) and control group (CG; $n=24 ; 75.36 \pm 5.21$ years). We evaluated the autonomic modulation by measuring the heart rate beat-to-beat for 30 min with the individual in supine rest using a heart rate monitor and assessed geometric indices (RRtri, TINN, SD1, SD2, SD1/SD2 ratio, and qualitative analysis of the Poincaré plot). Results: Significant reductions were found in RRtri, TINN, SD1, and SD2 indices among PDG compared to CG. Regarding the SD1/SD2 ratio, no significant changes were detected between the groups. The Poincaré plot demonstrated that individuals with PD had lower beat-to-beat dispersion in RR intervals, in addition to greater long-term dispersion of RR intervals compared to CG. Conclusions: The results suggest a reduction in the parasympathetic autonomic modulation and global variability in individuals with PD compared to controls, regardless of sex, age, and body mass index.
\end{abstract}

Keywords: Parkinson Disease; Autonomic Nervous System; Primary Dysautonomias; Neurodegenerative Diseases.

\begin{abstract}
RESUMO
Introdução: A doença de Parkinson (DP) produz alterações autonômicas, que indicam menor modulação parassimpática e variabilidade global, mas que devem ser investigadas quanto aos métodos geométricos. Objetivo: Investigar a modulação autonômica em indivíduos com DP, por meio de índices de variabilidade da frequência cardíaca (VFC) obtidos pelos métodos geométricos. Métodos: Estudo transversal, no qual foram avaliados 50 voluntários, divididos em dois grupos: o grupo doença de Parkinson (GDP; n=26; 75,36 $\pm 5,21$ anos) e o grupo controle (GC; $n=24 ; 75,36 \pm 5,21$ anos). Para a avaliação da modulação autonômica a frequência cardíaca foi captada batimento a batimento por meio de um cardiofrequencímetro com os indivíduos em decúbito dorsal por 30 min e índices geométricos da VFC foram avaliados (RRtri, TINN, SD1, SD2 e plot de Poincaré). Resultados: Houve reduções nos índices RRtri, TINN, SD1 e SD2 para o GDP em comparação ao GC. Para a relação SD1/SD2, diferenças significantes não foram observadas entre os grupos. 0 plot de Poincaré mostrou que indivíduos com DP têm menor dispersão batimento a batimento dos intervalos RR, bem como maior dispersão dos intervalos RR a longo prazo em relação ao GC. Conclusão: Os resultados sugerem haver diminuição da modulação autonômica parassimpática e da variabilidade global em indivíduos com DP em relação a indivíduos sem a doença, as quais são independentes de sexo, idade e índice de massa corporal.
\end{abstract}

Palavras-chave: Doença de Parkinson; Sistema Nervoso Autônomo; Disautonomias Primárias; Doenças Neurodegenerativas.

\footnotetext{
"Universidade Estadual Paulista “Júlio de Mesquita Filho”, Faculdade de Ciências e Tecnologia, Departamento de Fisioterapia, Presidente Prudente, São Paulo, Brazil. ${ }^{2}$ Oxford Brookes University, Faculty of Health and Life Sciences, Department of Biological and Medical Sciences, Oxford, United Kingdom.

Mileide Cristina STOCO-OLIVEIRA (D) http://orcid.org/0000-0002-8685-2786; Ana Laura RICCI-VITOR (D) https://orcid.org/0000-0002-3654-8532; Laís Manata VANZELLA (D) https://orcid.org/0000-0002-9494-3143; Heloisa Balotari VALENTE (D) https://orcid.org/0000-0003-3975-1904;

Vitor Eduardo dos Santos SILVA (DD https://orcid.org/0000-0002-9008-3086; Larissa Borba ANDRÉ (ID https://orcid.org/0000-0002-0525-8735; Augusto Cesinando de CARVALHO (D) https://orcid.org/0000-0002-3858-5740; David Matthew GARNER (D) https://orcid.org/0000-0002-8114-9055; Luiz Carlos Marques VANDERLEI (D) https://orcid.org/0000-0002-1891-3153

Correspondence: Heloisa Balotari Valente; E-mail: helobalov@hotmail.com

Support: This study was financed in part by the Coordenação de Aperfeiçoamento de Pessoal de Nivel Superior - Brasil (CAPES) - Finance Code 001.

Conflict of interest: There is no conflict of interest to declare.

Authors' contribution: Study conception and design: Mileide Cristina Stoco-Oliveira and Luiz Carlos Marques Vanderlei; Data collection: Mileide Cristina Stoco-Oliveira, Heloisa Balotari Valente, Vitor Eduardo dos Santos Silva, Larissa Borba André, and Augusto Cesinando de Carvalho; Data analysis: Ana Laura Ricci-Vitor, Laís Manata Vanzella, and David M. Garner; Manuscript drafting: Mileide Cristina Stoco-Oliveira, Luiz Carlos Marques Vanderlei, Ana Laura Ricci-Vitor, and Laís Manata Vanzella.
}

Received on March 7, 2020; Received in its final form on June 15, 2020; Accepted on June 25, 2020. 


\section{INTRODUCTION}

The autonomic nervous system (ANS) is divided into three parts: sympathetic, parasympathetic, and enteric ${ }^{1}$. Dysfunctions in these systems can cause distinct signs and symptoms, such as parasympathetic cholinergic failure, leading to urinary retention; sympathetic cholinergic failure, promoting a decline in sweating; sympathetic noradrenergic failure, causing orthostatic hypotension; enteric dysfunction, reducing peristalsis and, therefore, resulting in constipation².

Several of these changes are found in Parkinson's disease (PD). The ANS dysfunctions ${ }^{2}$ identified in PD may occur due to the presence of Lewy bodies at different parts of sympathetic and parasympathetic components of the ANS, such as the mid-lateral spine, the sympathetic paravertebral ganglia, the adrenal medulla, and the dorsal vagal nucleus ${ }^{3}$.

Given the changes promoted by PD in the ANS, the use of simple and non-invasive tools should be encouraged. Thus, the heart rate variability (HRV) can be adopted to evaluate these changes through interval oscillations between consecutive heart beats (RR intervals), showing the influence of ANS on the sinus node, as well as identify the individual's physiological health status. The HRV analysis can be performed in numerous ways, including geometric methods (triangular index - RRtri; triangular interpolation of RR interval histogram - TINN; and Poincaré plot), which convert the RR intervals into geometric patterns and allow analyzing the HRV by its geometric or graphic properties ${ }^{5}$.

TINN and RRtri are computed from the construction of a histogram density of normal RR intervals, with all possible $R R$ values in the $\mathrm{x}$-axis and their frequency in the $\mathrm{y}$-axis. The union of histogram points forms a shape similar to a triangle from which these indices are constructed ${ }^{4,5}$.

The Poincaré plot is a two-dimensional graphic strategy of consecutive $\mathrm{RR}$ intervals ${ }^{4,5}$. Its analysis can be visual, by evaluating the figure formed by its attractor, demonstrating the level of complexity of RR intervals, or quantitative, by adjusting the elliptical figure formed by the attractor, using the indices: SD1 (standard deviation of instantaneous beat-to-beat variability), SD2 (long-term standard deviation of continuous RR intervals), and SD1/SD2 ratio ${ }^{4}$. Many authors consider the Poincaré plot analysis to be grounded in nonlinear dynamics ${ }^{6}$. This assumption has gained attention, given the physiological evidence that the mechanisms involved in cardiovascular regulation interact with each other in a nonlinear and complex way ${ }^{7}$. These studies can provide important physiological interpretations of $\mathrm{HRV}^{6}$, as well as an improved understanding of the fluctuations that occur in the human body, both in health and disease ${ }^{8}$.

Investigations have shown that PD causes autonomic changes', among which a lower parasympathetic modulation and global variability stand out ${ }^{10}$. A better understanding of this imbalanced condition is vital, since the ANS controls part of the body's internal functions. Searches in the relevant scientific literature revealed few studies assessing the autonomic modulation using the measurable analysis of the Poincaré plot, no articles evaluating the plot qualitatively with individuals at rest, and no investigations that adopted RRtri and TINN in their analyses.

Thus, this work aims at contributing to the literature on the current theme by evaluating the autonomic modulation in individuals with PD through HRV indices obtained by geometric methods (RRtri, TINN, and Poincaré plots). We hypothesize that HRV indices from these methods can identify changes in the autonomic modulation of individuals with PD. This information is crucial for researchers and clinicians working with this population group, as it allows a better understanding of ANS dysfunctions in these subjects, which is central to explaining treatment strategies that can lessen these changes.

\section{METHODS}

This is a cross-sectional study, and all procedures were approved by the Research Ethics Committee of the Universidade Estadual Paulista, School of Science and Technology. All subjects were informed about the procedures and purposes of the study, and after agreement, they signed a confidential written informed consent form.

\section{Population and selection criteria}

The subjects were recruited at health clinics in the city of Presidente Prudente, São Paulo, Brazil. Individuals with PD should have been diagnosed with the disease at any time and be classified into stages 1 to 3, according to the Hoehn and Yahr (HY) Disability Stage Scale ${ }^{11}$. Participants without the disease were assigned to the control group (CG) and paired by age and sex to the subjects with PD. Additionally, to ensure the understanding of the procedures performed, only individuals without cognitive deficits, as assessed by the Mini-Mental State Examination (MMSE) ${ }^{12}$, were considered for both groups.

Smokers, alcoholics, individuals with infections and cardiovascular and respiratory diseases known to interfere with cardiac autonomic control, and those who did not sign the informed consent form were excluded. Likewise, we excluded subjects who presented more than $5 \%$ of errors in the series of RR intervals.

\section{Experimental protocol}

The datasets were collected in two phases, with intervals ranging from 24 hours to one week between them, all performed during the "on" period of levodopa for PD subjects ${ }^{13}$. The first stage involved gathering personal data and performing physical and clinical evaluations. In the second period, the autonomic assessment was completed, and the participants were released. 
The datasets were recorded in a room with a temperature between 21 and $23^{\circ} \mathrm{C}$ and humidity of 40 to $60 \%$ between 08:00 and 12:00 a.m. to minimize the influence of the circadian rhythm ${ }^{14}$. The individuals were asked to avoid consuming alcoholic beverages and/or stimulants, such as coffee, tea, or chocolate, in the preceding 12 hours and to use their medication as usual. The evaluations were carried out individually.

\section{Physical and clinical evaluations}

After individual data collection, the subjects were assessed for body composition (body weight, height, and body mass index - BMI), cardiovascular parameters, the stage of $\mathrm{PD}$, and cognition.

Body weight was measured with a digital scale (Welmy R/I 200, Santa Bárbara D’Oeste, São Paulo, Brazil), and height was obtained using a stadiometer (Sanny, São Paulo, Brazil). Based on these measurements, the BMI was calculated by the mathematical formula: weight $/$ height ${ }^{2}\left(\mathrm{~kg} / \mathrm{m}^{2}\right)$, leading to the classification of body composition ${ }^{15}$.

Body fat percentage and lean mass were obtained through the Maltron BF 906 Body Fat Analyzer (Maltron, UK) bioimpedance equipment with the participant in a supine position on a non-conductive surface lacking metallic contacts and focused on remaining at rest during the procedure ${ }^{16}$.

Systolic and diastolic blood pressures were confirmed with an aneroid sphygmomanometer (WelchAllyn - Tycos, New York, USA) and a stethoscope (Littman, Saint Paul, Minnesota, USA). The pressures were indirectly measured in the left arm and classified according to the criteria established by the VII Brazilian Guideline of Arterial Hypertension ${ }^{17}$. The resting heart rate (HR) was recorded with the same HR monitor used to evaluate the HRV (Polar RS800CX, Polar Electro, Kempele, Finland).

The disease stage assessment was performed based on the HY scale, which evaluates the individual's disability according to their signs and symptoms ${ }^{11}$. The cognitive evaluation involved the administration of the MMSE, which assesses this function based on the following domains: spatial orientation, temporal memory, immediate memory, recall, calculation, language-naming, repetition, comprehension, script, and diagram reproduction ${ }^{12}$.

\section{Autonomic system assessment}

For the investigation of autonomic modulation, the HR beat-to-beat was obtained by an HR monitor (Polar RS800CX, Polar Electro, Kempele, Finland). To this end, the subjects rested in the supine position on a stretcher for 30 minutes. They were asked to stay awake, breathe spontaneously, and avoid conversation throughout the procedure.

The datasets collected were transferred to the Polar Precision Performance SW software (v. 4.01.029). The series of RR intervals initially obtained underwent digital filtering performed by the software with a moderate filter ${ }^{4}$, followed by manual filtering in the Microsoft Excel software to eliminate premature ectopic beats and artifacts. Only series with more than $95 \%$ of sinus beats were included in the study ${ }^{18}$. The autonomic modulation analysis consisted of sections with 1000 consecutive RR intervals ${ }^{19}$, and the Kubios ${ }^{\circledR}$ HRV software, version 3.125, was used to calculate HRV indices.

Geometric methods were adopted to analyze HRV, and the following indices were obtained: RRtri, TINN, and indices extracted from the Poincaré plot (SD1, SD2, SD1/SD2 ratio).

RRtri was calculated from the density histogram of normal RR intervals, involving the histogram integral (the total number of RR intervals) divided by the maximum of the density distribution (modal frequency of RR intervals), measured on a discrete scale with sections of $7.8125 \mathrm{~ms}(1 / 128 \mathrm{~s})^{20}$. TINN consists of the baseline width of the distribution measured as the basis of a triangle, and the least-squares difference was used to determine the triangle ${ }^{20}$.

The Poincaré plot is a map of points in Cartesian coordinates, with each $\mathrm{RR}$ interval represented on the $\mathrm{x}$-axis by the previous RR interval and on the y-axis by the following interval, a figure that allows quantitative and qualitative analysis. The Poincaré plot was quantitatively investigated using the following indices: SD1, SD2, and SD1/SD2 ratio $^{20}$. The qualitative analysis of the plot was performed based on the shapes formed by the attractor, which were described by Tulppo et al. ${ }^{21}$ as:

1) Figure in which the RR interval dispersion increases with increase in the RR intervals, characteristic of a normal plot;

2) Figure with low overall beat-to-beat dispersion and no increase in RR interval dispersion in the long term.

\section{Data analysis}

Descriptive statistical techniques were applied to describe the population profile data, and results were presented as mean, standard deviation, and percentage.

To match the HRV geometric indices in the CG and PDG and in stages 1-2 and 3 of HY, analyses of covariance (ANCOVA) were carried out and adjusted for potential confounding factors controlled by their direct relationship with autonomic modulation. These adjustment factors were: gender, age, and BMI. We used the Fisher's test to investigate whether there was a difference between the medications of the groups.

The qualitative analysis of the Poincaré plot was performed using a scatter plot from the Microsoft Excel software, including all volunteers. The assessment of data normality was determined by the Shapiro-Wilk test. We measured the effect size of the differences between groups by eta squared. Effect sizes were considered small from $\geq 0.01$ to $<0.06$, moderate from $\geq 0.06$ to $<0.14$, and high when $\geq 0.1428^{22}$. The significance level was set at $5 \%$ for all tests and the confidence interval at 95\%. We used the SPSS statistical software (v. 13.0; SPSS Inc., Chicago, IL, USA) for the statistical assessments.

The power of the study was calculated in the software from the website www.lee.dante.br. For the SD1 index 
variable, it assumed a significant difference of $7 \mathrm{~ms}$ and standard deviation of $6 \mathrm{~ms}$, based on the number of subjects analyzed and the 5\% significance level (two-tailed) established at a power greater than $80 \%$ to detect changes between variables.

\section{RESULTS}

Figure 1 illustrates the subject's distribution and sample loss throughout the stages.

Table 1 presents the group features. Significant differences were detected in the diastolic blood pressure, BMI, and MMSE variables $(\mathrm{p}<0.05)$, but not in the variables age, systolic blood pressure, HR, body fat, lean mass, body weight, and height $(p>0.05)$. Overweight ${ }^{15}$, prehypertension ${ }^{17}$, absence of cognitive deficits ${ }^{12}$, and PDG individuals were identified in stage two of $\mathrm{PD}^{11}$. Significant differences were revealed in Table 2 with regard to dopamine antagonists, levodopa, and antidepressants.

Table 3 compares the geometric HRV indices between CG and PDG. Statistically significant reductions were found in
Table 1. Characterization of the control and Parkinson's disease groups evaluated in the study.

\begin{tabular}{lccc|}
\hline & CG $(n=24)$ & PDG $(n=26)$ & -value \\
\hline Age (years) & $70.25 \pm 8.02$ & $72.76 \pm 7.64$ & 0.261 \\
\hline SBP $(\mathrm{mmHg})$ & $130.41 \pm 13.34$ & $126.15 \pm 12.02$ & 0.241 \\
\hline DBP $(\mathrm{mmHg})$ & $86.66 \pm 8.68$ & $79.61 \pm 10.38$ & 0.013 \\
\hline HR (bpm) & $62.75 \pm 12.93$ & $64.92 \pm 9.10$ & 0.493 \\
\hline Body fat (\%) & $32.08 \pm 9.54$ & $33.04 \pm 8.62$ & 0.712 \\
\hline Lean mass (\%) & $67.83 \pm 9.48$ & $66.95 \pm 8.62$ & 0.732 \\
\hline Body weight (kg) & $78.25 \pm 10.77$ & $72.94 \pm 13.74$ & 0.137 \\
\hline Height (m) & $1.63 \pm 0.06$ & $1.63 \pm 0.09$ & 0.783 \\
\hline BMI & $29.42 \pm 4.04$ & $27.02 \pm 4.01$ & 0.044 \\
\hline MMSE & $26.87 \pm 3.12$ & $24.57 \pm 4.47$ & 0.042 \\
\hline Diagnosis time & ---- & $6.57 \pm 5.27$ & ---- \\
(years) & ----- & $2.34 \pm 0.62$ & ---- \\
\hline HY Scale & & & \\
\hline
\end{tabular}

Meantstandard deviation. CG: control group; PDG: Parkinson's disease group; SBP: systolic blood pressure; DBP: diastolic blood pressure; HR: heart rate; BMI: body mass index; HY: Hoehn and Yahr Disability Stage Scale; MMSE: Mini-Mental State Examination; mmHg: millimeters of mercury; bpm: beats per minute; \%: percentage; kg: kilograms; m: meters.

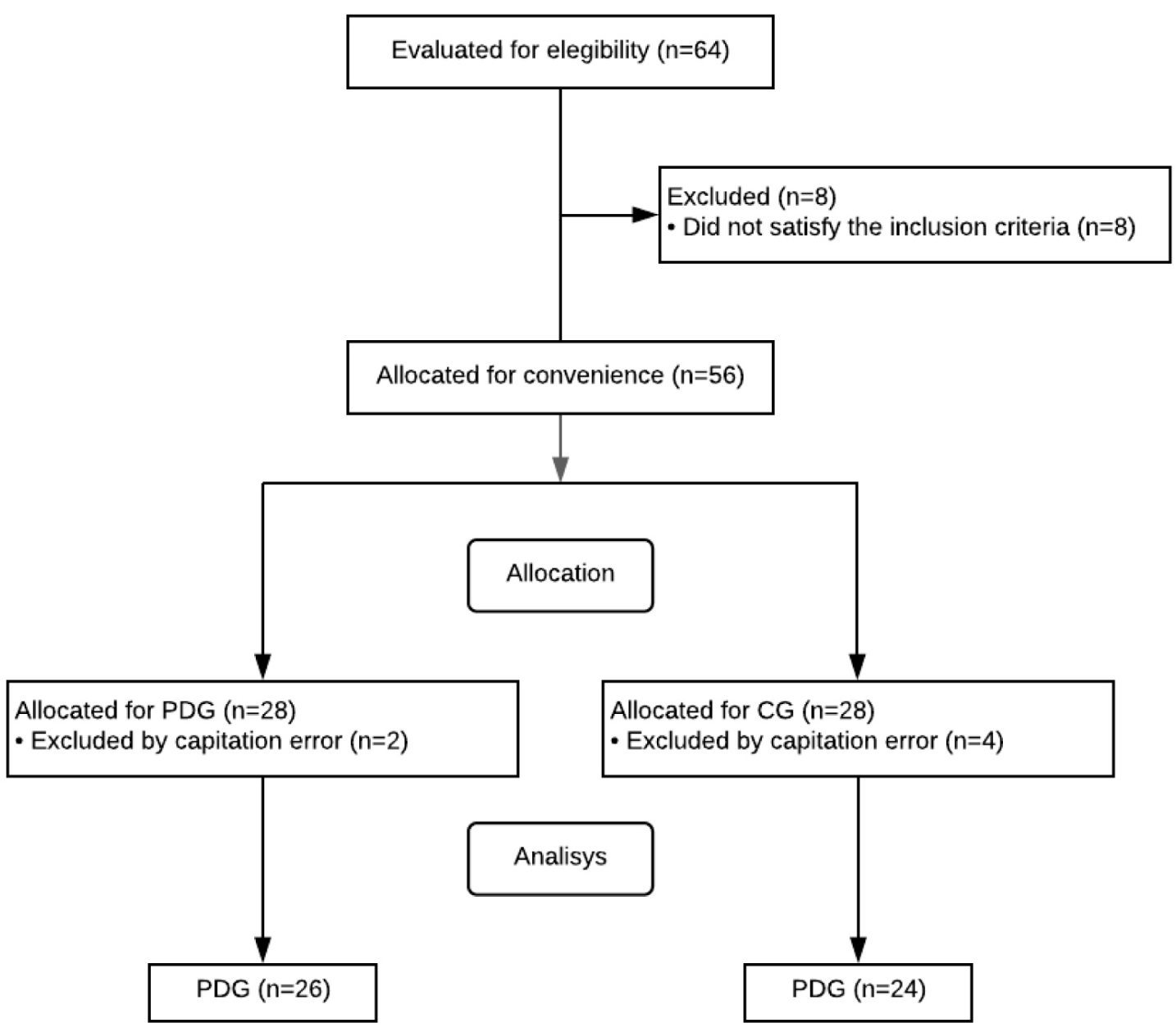

Figure 1. Sample loss flowchart. 
Table 2. Medication used by volunteers of the control and Parkinson's disease groups evaluated in the study.

\begin{tabular}{|c|c|c|c|}
\hline Medication (\%) & $C G(n=24)$ & PDG $(n=26)$ & p-value \\
\hline Dopamine antagonists & 0.0 & 30.8 & 0.004 \\
\hline Platelet antiaggregant & 20.8 & 23.1 & 1.0 \\
\hline Antiarrhythmic drugs & 0.0 & 11.5 & 0.23 \\
\hline Anticholinergic & 0.0 & 7.7 & 0.49 \\
\hline Antidepressants & 4.2 & 30.8 & 0.024 \\
\hline Beta-blocker & 8.3 & 19.2 & 0.42 \\
\hline Biguanides & 16.7 & 19.2 & 1.0 \\
\hline Ca+ channel blocker & 8.3 & 7.7 & 1.0 \\
\hline $\begin{array}{l}\text { Angiotensin II receptor } \\
\text { blockers }\end{array}$ & 41.7 & 34.6 & 0.77 \\
\hline Ciprofibrate & 0.0 & 3.8 & 1.0 \\
\hline $\begin{array}{l}\text { Amantadine } \\
\text { Hydrochloride }\end{array}$ & 0.0 & 15.4 & 0.11 \\
\hline Diuretic & 25.0 & 15.4 & 0.49 \\
\hline Entacapone & 0.0 & 7.7 & 0.49 \\
\hline Statins & 29.2 & 23.1 & 0.75 \\
\hline Gliclazide & 8.3 & 7.7 & 1.0 \\
\hline ACE inhibitor & 12.5 & 0.0 & 0.10 \\
\hline MAO inhibitor & 0.0 & 15.4 & 0.11 \\
\hline Levodopa & 0.0 & 69.2 & 0.000 \\
\hline Others & 66.7 & 69.2 & 1.0 \\
\hline Vasodilator & 4.2 & 15.4 & 0.35 \\
\hline
\end{tabular}

CG: control group; PDG: Parkinson's disease group; \%: percentage; Ca+: calcium; ACE: angiotensin-converting enzyme; MAO: monoamine oxidase. the PDG for RRtri, TINN, SD1, and SD2 indices ( $\mathrm{p}<0.05)$, but not in SD1/SD2 ratio ( $p>0.05)$.

Figure 2 displays the visual representation of the Poincaré plot pattern of the evaluated groups. This representation required the $R R$ intervals of all subjects examined in the study to plot the chart.

Table 4 shows the comparison of geometric HRV indices between participants with PD stages $1-2$ and 3 according to

Table 3. Comparison of the geometric indices of heart rate variability between the control and Parkinson's disease groups, adjusted for gender, age, and body mass index.

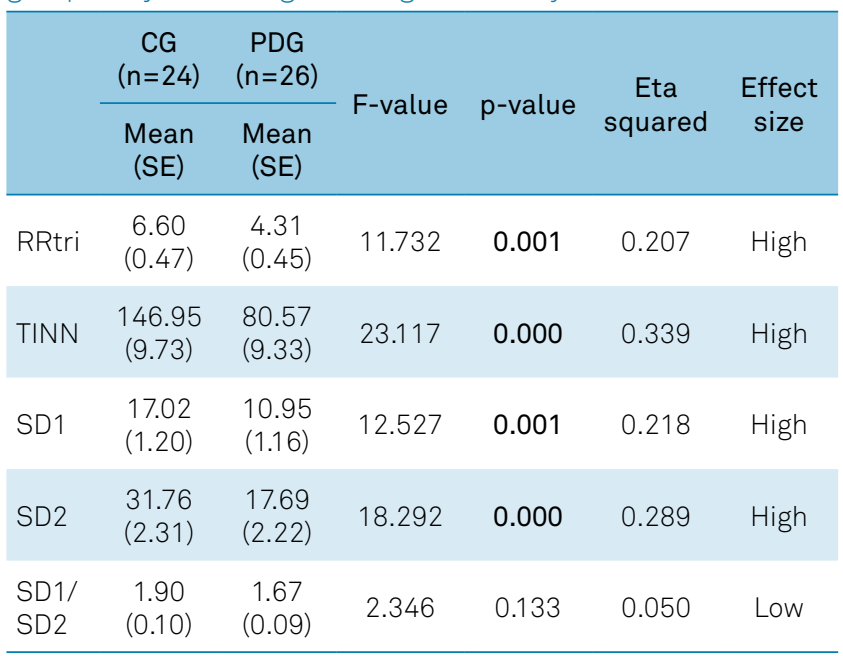

BMI: body mass index; CG: control group; PDG: Parkinson's disease group; SE: standard error; F: Coefficient of the measure of variance between groups by the variance within groups; RRtri: triangular index; TINN: triangular interpolation of RR interval histogram; SD1: standard deviation of instantaneous beat-to-beat variability; SD2: long-term standard deviation of continuous RR intervals.

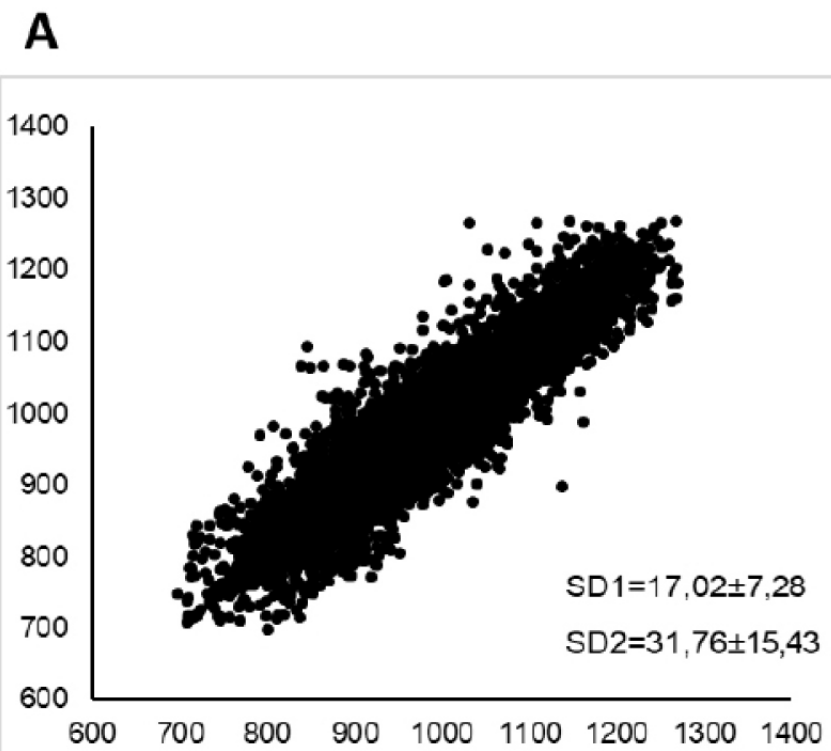

\section{B}

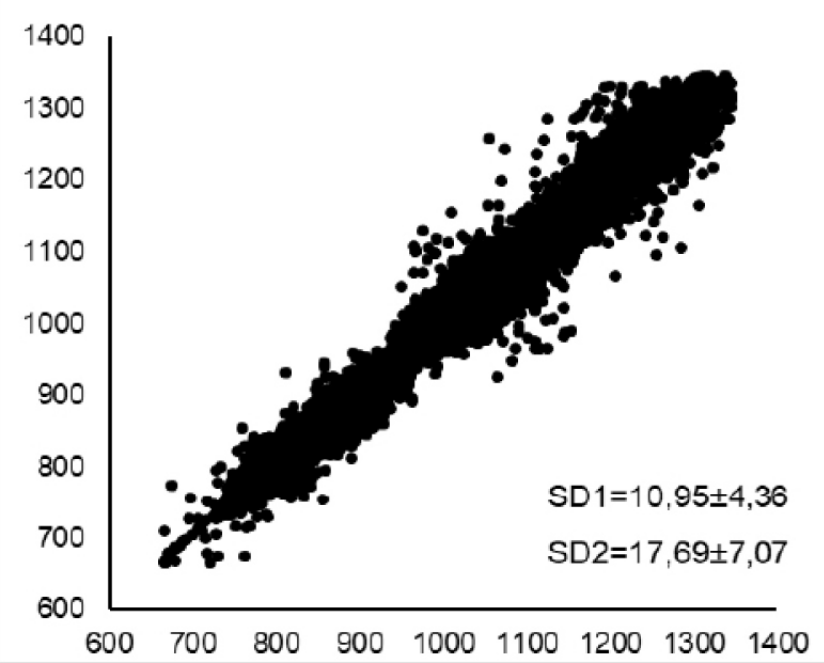

Figure 2. Scatter plot representing the qualitative analysis of Poincaré plot observed in control (Graphic A) and Parkinson's disease (Graphic B) groups. 
Table 4. Comparison between Parkinson's disease participants in disease stages 1-2 and 3 according to the Hoehn and Yahr Disability Stage Scale.

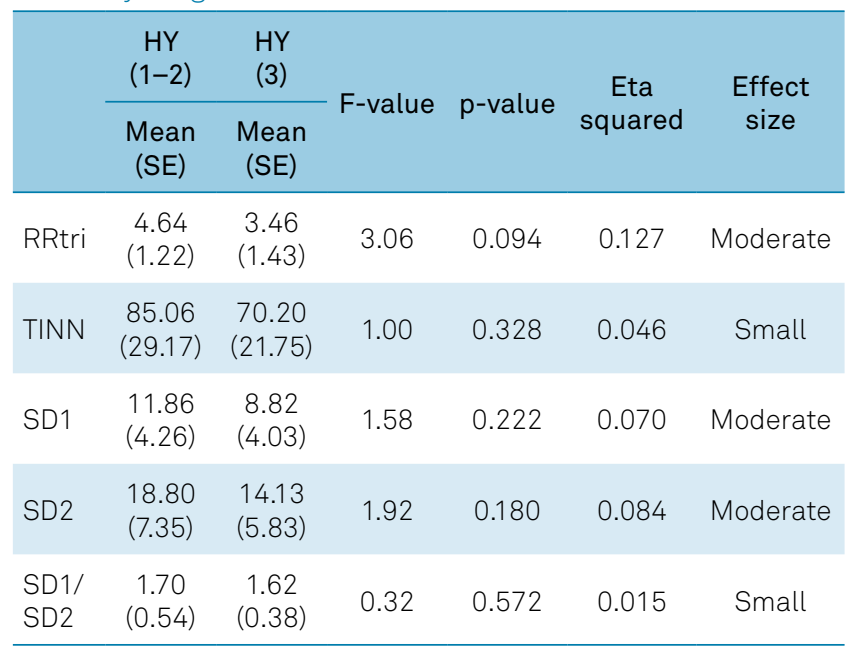

HY:Hoehn and Yahr Disability Stage Scale; SE: standard error; F: Coefficient of the measure of variance between groups by the variance within groups; RRtri: triangular index; TINN: triangular interpolation of RR interval histogram; SD1: standard deviation of instantaneous beat-to-beat variability; SD2: long-term standard deviation of continuous RR intervals.

the HY Disability Stage Scale. No significant difference was identified between the groups ( $p>0.05)$.

\section{DISCUSSION}

The results obtained by the Poincaré plot visual analysis and the geometric HRV indices confirmed that PD individuals presented reduced global variability and parasympathetic modulation, irrespective of possible confounding factors, such as gender, age, and BMI. Furthermore, no differences were found in the autonomic modulation of participants with stages 1-2 and 3 of the HY Disability Stage Scale. Consequently, all PD individuals were allocated in the PDG.

In the description of PDG subjects, the analyzed participants represent the general PD population, given the high proportion of males ${ }^{24}$ and older adults ${ }^{25}$. The subjects had a mean time of diagnosis of $6.57 \pm 5.27$ years, which can be considered low considering the variation from 1 to 30 years described in the medical literature ${ }^{26}$. The results obtained by the HY scale ${ }^{11}$ showed that most subjects presented impairment on both sides of the body but no balance deficit ${ }^{11}$.

Regardless of the pharmacotherapy, a substantial difference was found between PDG and CG concerning the classes of dopamine antagonists and levodopa, which are specific for the treatment of PD. Also, the groups showed a significant difference as to classes of antidepressants. In PDG, $30.8 \%$ of subjects used this medication, while its use in CG corresponded to $4.2 \%$ of subjects; this difference is in agreement with the literature, which describes depression as very common in subjects with $\mathrm{PD}^{27}$. In addition, although some studies indicate a negative influence of antidepressants on autonomic modulation, the literature only reports evidence against the class of tricyclic antidepressants ${ }^{28}$, prescribed for only one individual in the PDG, suggesting that this difference did not influence our results.

The SD1 index, which reflects the parasympathetic modulation ${ }^{4}$, was lower in the PDG compared to the CG and had a high effect size. These results confirm that subjects with PD have a reduced parasympathetic modulation. A similar finding was identified in the study by Rocha et al. ${ }^{10}$, who also estimated the SD1 index in individuals with PD at rest and discovered a reduction in parasympathetic modulation in these subjects compared to individuals without the disease. This decrease in vagal function has been linked to an increase in morbidity and mortality ${ }^{29}$.

The global variability indices RRtri, TINN, and SD2 were also reduced in PD individuals compared to those without the disease and showed a high effect size. The SD2 index is comparable to that of Rocha et al. ${ }^{10}$, who detected a difference of $14.41 \mathrm{~ms}$ between groups of volunteers in 15 minutes rest, a value very similar to the one found in this study - $14.07 \mathrm{~ms}$. No important difference in the SD1/ SD2 ratio was found between the groups, which can be explained by the reduction in both SD1 and SD2 indices in subjects with PD.

The decrease in global variability and parasympathetic modulation can be qualitatively detected in the Poincaré plot of the groups evaluated (Figure 2). The Poincaré plot visual analysis confirmed that PD individuals have a lower beatto-beat RR interval dispersion, as the shape of the plot was linear, indicating that PD subjects have reduced parasympathetic modulation when compared to individuals without the disease, as their plot displayed a larger beat-to-beat dispersion. Moreover, the long-term distribution of RR intervals in the PDG presented a higher concentration of points to the right of the plot, suggesting the presence of RR intervals with higher values in this group. This result corroborates the study by Haapaniemi et al. ${ }^{23}$, who presented the plot with a 24-hour electrocardiogram (ECG) analysis and detected a lower dispersion in PD compared to controls.

These findings confirm the importance of the intervention in individuals with PD so as to promote a superior response of the parasympathetic and global modulation, as well as reduce possible system damage, as in the initial stages of PD, when cardiovagal dysfunction occurs due to the decline in ANS branches ${ }^{30}$.

The current study presents some limitations. Its crosssectional design makes it impossible to survey the autonomic behavior of these subjects, restricting the evaluation of the temporal evolution of the disease. In addition, individuals with PD in phases 4 and 5 of HY were not included. The large number of medications taken by subjects from 
both groups should also be considered a study limitation. Furthermore, we must take into account that all PDG participants were assessed during the levodopa "on" period and that a detailed account should be taken of the medications used by each group.

Despite these limitations, this study is, to our knowledge, the first to evaluate RRtri and TINN indices and perform a qualitative analysis of the Poincaré plot in resting individuals with PD. Also, the assessments performed with adjustment for potential confounding factors (gender, age, BMI) can be considered one of the strong points of the study.

In summary, the results suggest that individuals with PD present a reduced global variability and parasympathetic modulation compared to individuals without the disease, regardless of likely confounding factors, such as gender, age, and BMI. These findings show the need for prevention and treatment of PD subjects through interventions that may encourage HRV increases in this population.

\section{References}

1. Orimo S, Ghebremedhin E, Gelpi E. Peripheral and central autonomic nervous system: does the sympathetic or parasympathetic nervous system bear the brunt of the pathology during the course of sporadic PD? Cell Tissue Res. 2018 Jul;373(1):267-86. https://doi.org/10.1007/ s00441-018-2851-9

2. Leclair-Visonneau L, Magy L, Volteau C, Clairembault T, Dily SL, Préterre $\mathrm{C}$, et al. Heterogeneous pattern of autonomic dysfunction in Parkinson's disease. J Neurol. 2018 Apr;265(4):933-41. https://doi. org/10.1007/s00415-018-8789-8

3. den Hartog Jager WA, Bethlem J. The distribution of Lewy bodies in the central and autonomic nervous systems in idiopathic paralysis agitans. J Neurol Neurosurg Psychiatry. 1960 Nov;23(4):283-90. https://doi.org/10.1136/jnnp.23.4.283

4. Vanderlei LCM, Pastre CM, Hoshi RA, Carvalho TD, Godoy MF. Noções básicas de variabilidade da frequência cardíaca e sua aplicabilidade clínica. Rev Bras Circ Cardiovasc. 2009 Apr-Jun;24(2):205-17. https://doi.org/10.1590/S010276382009000200018

5. Vanderlei LCM, Pastre CM, Freitas Júnior IF, Godoy MF. Índices geométricos de variabilidade da frequência cardíaca em crianças obesas e eutróficas. Arq Bras Cardiol. 2010 Jul;95(1):35-40. https:// doi.org/10.1590/S0066-782X2010005000082

6. Khaled AS, Owis MI, Mohamed ASA. Employing time-domain methods and Poincaré plot of heart rate variability signals to detect congestive heart failure. BIME Journal. 2006 Jan;6(1):35-41.

7. Huikuri HV, Mäkikallio TH, Perkiömäki J. Measurement of heart rate variability by methods based on nonlinear dynamics. $J$ Electrocardiol. 2003 Dec;36 Suppl:95-9. https://doi.org/10.1016/j. jelectrocard.2003.09.021

8. Higgins JP. Nonlinear systems in medicine. Yale J Biol Med. 2002 Sep-Dec;75(5-6):247-60

9. Brisinda D, Sorbo AR, Di Giacopo R, Venuti A, Bentivoglio AR, Fenici R Cardiovascular autonomic nervous system evaluation in Parkinson disease and multiple system atrophy. J Neurol Sci. 2014 Jan;336(12):197-202. https://doi.org/1010.1016/j.jns.2013.10.039

10. Rocha RSB, Rocha LSO, Pena ESM, Caldas LCP, Moreno MA. Analysis of autonomic modulation of heart rate in patients with Parkinson's disease and elderly individuals submitted to game therapy training. Geriatr Gerontol Int. 2018 Jan;18(1):20-5. https://doi.org/10.1111/ ggi.13130

11. Hoehn MM, Yahr MD. Parkinsonism: onset, progression, and mortality. Neurology. 1967 May;17(5):427-42. https://doi. org/10.1212/wnl.17.5.427

12. Bertolucci PHF, Brucki SMD, Campacci SR, Juliano Y. O Mini-Exame do Estado Mental em uma população geral:impacto da escolaridade. Arq Neuro-Psiquiatr. 1994 Mar;52(1):1-7. https://doi.org/10.1590/ S0004-282X1994000100001

13. Carpenter MG, Allum JHJ, Honegger F, Adkin AL, Bloem BR. Postural abnormalities to multidirectional stance perturbations in Parkinson's disease. J Neurol Neurosurg Psychiatry. 2004 Sep;75(9):1245-54. https://doi.org/10.1136/jnnp.2003.021147

14. Boudreau P, Dumont G, Kin NM, Walker CD, Boivin DB. Correlation of heart rate variability and circadian markers in humans. Annu Int Conf IEEE Eng Med Biol Soc. 2011 Aug-Sep;2011:681-2. https://doi. org/10.1109/IEMBS.2011.6090153

15. Associação Brasileira para o Estudo da Obesidade e da Síndrome Metabólica. Diretrizes brasileiras de obesidade 2016. 4th ed. São Paulo:ABESO; 2016. p. 1-186.

16. Lukaski HC. Methods for the assessment of human body composition: traditional and new. Am J Clin Nutr. 1987 Oct;46(4):53756. https://doi.org/10.1093/ajcn/46.4.537

17. Malachias MVB, Souza WKSB, Plavnik FL, Rodrigues CIS, Brandão AA, Neves MFT, et al. 7a Diretriz Brasileira de Hipertensão Arterial. Arq Bras Cardiol. 2016 Sep;107(3 Supl. 3):1-83. https://doi. org/10.5935/abc.20160152

18. Godoy MF, Takakura IT, Correa PR. Relevância da análise do comportamento dinâmico não-linear (Teoria do Caos) como elemento prognóstico de morbidade e mortalidade em pacientes submetidos à cirurgia de revascularização miocárdica. Arq Ciênc Saúde. 2005 Oct-Dec;12(4):167-71.

19. Niskanen JP, Tarvainen MP, Ranta-Aho PO, Karjalainen PA. Software for advanced HRV analysis. Comput Methods Programs Biomed. 2004 Oct;76(1):73-81. https://doi.org/10.1016/j.cmpb.2004.03.004

20. Task Force of the European Society of Cardiology and the North American Society of Pacing and Electrophysiology. Heart rate variability: standards of measurement, physiological interpretation and clinical use. Circulation. 1996 Mar;93(5):1043-65. https://doi. org/10.1161/01.cir.93.5.1043

21. Tulppo MP, Mäkikallio TH, Seppänen T, Laukkanen RT, Huikuri HV. Vagal modulation of heart rate during exercise: effects of age and physical fitness. Am J Physiol. 1998 Feb;274(2):H424-9. https://doi. org/10.1152/ajpheart.1998.274.2.H424

22. Maher JM, Markey JC, Ebert-May D. The other half of the story: effect size analysis in quantitative research. CBE Life Sci Educ. 2013 Fall;12(3):345-51. https://doi.org/10.1187/cbe.13-04-0082

23. Haapaniemi TH, Pursiainen V, Korpelainen JT, Huikuri HV, Sotaniemi KA, Myllylä VV. Ambulatory ECG and analysis of heart rate variability in Parkinson's disease. J Neurol Neurosurg Psychiatry. 2001 Mar;70(3):305-10. https://doi.org/10.1136/jnnp.70.3.305

24. Hirsch L, Jette N, Frolkis A, Steeves T, Pringsheim T. The incidence of Parkinson's disease: a systematic review and meta-analysis. Neuroepidemiology. 2016 May;46(4):292-300. https://doi. org/10.1159/000445751

25. Dorsey ER, Constantinescu R, Thompson JP, Biglan KM, Holloway RG, Kieburtz K, et al. Projected number of people with Parkinson disease in the most populous nations, 2005 through 2030. Neurology. 2007 Jan;68(5):384-6. https://doi.org/10.1212/01. wnl.0000247740.47667.03 
26. Moreira CS, Martins KFC, Neri VC, Araújo PG. Doença de Parkinson: como diagnosticar e tratar. Rev Científica FMC. 2007;2(2):19-29.

27. Rodgers SH, Schütze R, Gasson N, Anderson RA, Kane RT, Starkstein $S$, et al. Modified mindfulness-based cognitive therapy for depressive symptoms in Parkinson's disease: a pilot trial. Behav Cogn Psychother. 2019 Jul;47(4):446-61. https://doi.org/10.1017/ S135246581800070X.

28. Kemp AH, Quintana DS, Gray MA, Felmingham KL, Brown K, Gatt JM. Impact of depression and antidepressant treatment on heart rate variability: a review and meta-analysis. Biol Psychiatry. 2010 Jun;67(11):1067-74. https://doi.org/10.1016/j.biopsych.2009.12.012

29. Thayer JF, Lane RD. The role of vagal function in the risk for cardiovascular disease and mortality. Biol Psychol. 2007 Feb;74(2):224-42. https://doi.org/10.1016/j.biopsycho.2005.11.013

30. Delgado G, Estañol B, Rodríguez-Violante M, Martínez-Memije R, Infante-Vázquez O, Bertado-Ramírez N. Cardiovascular variability in Mexican patients with Parkinson's disease. Arq Neuro-Psiquiatr. 2014 Oct;72(10):762-67. https://doi.org/10.1590/0004-282X20140125 